\title{
USULAN PENUGASAN DENGAN METODE HUNGARIAN SEBAGAI ALAT MENINGKATKAN EFISIENSI DI BAGIAN FINISHING (Studi Kasus di PT Duaroda Saranatama)
}

\author{
Yuta Ardianti Putri ${ }^{1)}$, Zeny Fatimah Hunusalela ${ }^{2)}$, Elfitria Wiratmani ${ }^{3)}$ \\ ${ }^{1)}$ Teknik Industri, Fakultas Teknik dan Ilmu Komputer, Universitas Indraprasta PGRI \\ ${ }^{2)}$ Teknik Industri, Fakultas Teknik dan Ilmu Komputer, Universitas Indraprasta PGRI \\ ${ }^{3)}$ Teknik Industri, Fakultas Teknik dan Ilmu Komputer, Universitas Indraprasta PGRI
}

\begin{abstract}
ABSTRAK
Dengan meningkatnya kebutuhan hidup manusia, jenis-jenis pekerjaan pun mulai bermunculan. Namun variasi pekerjaan ini tidak selamanya cocok dengan setiap individu yang mengerjakannya. Hal inilah yang berpotensi memunculkan kesalahan-kesalahan dalam pekerjaan tersebut. Salah satu cara umum yang biasa digunakan untuk meminimalkan kesalahan dalam pekerjaan adalah dengan penugasan atau assignment. PT Duaroda Saranatama merupakan perusahaan yang bergerak di bidang industri Rotational Moulding. Sebagai upaya untuk menyusun penugasan yang optimal di PT Duaroda Saranatama, digunakanlah metode Hungarian. Hungarian method merupakan metode untuk menentukan alokasi sumber daya ke suatu tugas terterntu secara satu persatu (one by one). Penelitian ini dilakukan untuk mengetahui lamanya pengerjaan penyelesaian produk cooler box di PT Duaroda Saranatama tepatnya dibagian finishing, mengetahui penempatan pekerja dengan mesin yang dioperasikannya berdasarkan waktu baku pengerjaan per pekerja, mengetahui penempatan pekerja berdasarkan jumlah kesalahan pada bagian finishing di PT Duaroda Saranatama. Dengan penugasan berdasarkan pada waktu pengerjaan akan menekan waktu agar produk yang dihasilkan selesai sesuai dengan waktu yang telah ditentukan. Penempatan pekerja berdasarkan proporsi kesalahan dilakukan dengan menempatkan Grup 1 untuk pengerjaan produk Big C'Frut, grup 2 untuk pengerjaan produk Susu Nasional, Grup 3 untuk pengerjaan Bintang Radler, Grup 4 untuk pengerjaan produk KPBS Pengalengan.
\end{abstract}

(Kata Kunci : Penugasan, Assignment, Hungarian)

\section{PENDAHULUAN}

Kesalahan dalam pekerjaan sejatinya dapat dikurangi. Pengurangan kesalahan pada pekerjaan dimaksudkan untuk meningkatkan efektifitas pekerjaan dan efisiensi perusahaan (Assiddiq, Pudjo, \& Bambang, 2014). Salah satu cara umum yang biasa digunakan untuk meminimalkan kesalahan dalam pekerjaan adalah dengan penugasan atau assignment (Basriati \& Lestari, 2017).

PT Duaroda Saranatama merupakan perusahaan yang bergerak dibidang industri Rotational Moulding. Rotational moulding atau yang juga disebut rotamoulding adalah teknologi pencetakan plastik yang ideal untuk menciptakan produk dengan rongga. Ini merupakan teknik penuangan bahan plastik kecetakan yang berbeda dengan proses pembuatan bahan plastik lainnya karena pada teknik ini tidak menggunakan tekanan dalam pencetakan.

Sebagai upaya untuk menyusun penugasan yang optimal di PT Duaroda Saranatama, digunakanlah metode Hungarian. Hungarian method merupakan metode untuk menentukan alokasi sumber daya ke suatu tugas terterntu secara satu persatu (one by one) (Ndururu, Waruwu, \& Yanny, 2017). Pada Metode Hungarian, jumlah sumber-sumber yang ditugaskan harus samapersis dengan jumlah tugas yang akan diselesaikan. Setiap sumber harusditugaskan hanya untuk satu tugas (Harini, 2017).

Semua teknis penempatan pekerja di PT Duaroda Saranatamakhususnya di bagian finishing masih belum disusun secara baik. Kebutuhan untuk adanya penempatan pekerja dalam prosedur operasional ini juga dirasakan 
beberapa karyawan di PT Duaroda Saranatama. Hal ini berkaitan dengan adanya pergantian/penambahan karyawan baru. Saat ini belum ada literatur yang dapat dipakai sebagai acuan dalam penempatan pekerja yang sesuai. Hal ini mengakibatkan proses produksi tidak dapat dilakukan dengan maksimal.

Penugasan dinilai sangat penting dikarenakan jumlah pesanan permintaan dari konsumen yang meningkat cukup pesat. Pesanan yang meningkat di PT Duaroda Saranatama dapat dilihat melalui tabel Permintaan barang berikut ini:

Tabel 1. Permintaan Barang

\begin{tabular}{|c|c|c|c|}
\hline $\begin{array}{ll}\text { Konsumen } & \text { Bulan } \\
\end{array}$ & $\begin{array}{r}\text { Juni } \\
\text { (Unit) }\end{array}$ & $\begin{array}{c}\text { Juli } \\
\text { (Unit) }\end{array}$ & \begin{tabular}{|c} 
Agustus \\
(Unit)
\end{tabular} \\
\hline PT. Sinar Sosro & & & 80 \\
\hline PT. Aje Indonesia & 600 & 1000 & 1300 \\
\hline PT. Multi Bintang Indonesia Niaga & 100 & 50 & \\
\hline PT. Prima Usaha Era Mandiri & & 8 & 10 \\
\hline PT. Blue Ocean Sejahtera & & & 200 \\
\hline PT. Bumi Serpong Damai & 255 & 137 & \\
\hline PT. Tirta Fresindo Jaya & & 150 & \\
\hline PT. Catur Manunggal Elektromekanik & 203 & & \\
\hline Jumlah & 1158 & 1345 & 1590 \\
\hline
\end{tabular}

(Sumber: PT Duaroda Saranatama)

Data diatas merupakan data PO (Purchasing Order) berkelanjutan yang ada di PT Duaroda Saranatama. Data di atas merupakan data umum permintaan barang di PT. Duaroda Saranatama berdasarkan konsumen. Dari data di atas, permintaan konsumen dapat dibedakan berdasarkan jenis barang yang dipesan. Berikut merupakan daftar barang yang dipesan:

Tabel 2. Daftar Pesanan Barang

\begin{tabular}{|l|c|c|c|}
\hline Benis & $\begin{array}{c}\text { Juni } \\
\text { (Unit) }\end{array}$ & $\begin{array}{c}\text { Juli } \\
\text { (Unit) }\end{array}$ & $\begin{array}{c}\text { Agustus } \\
\text { (Unit) }\end{array}$ \\
\hline Cooler Box & 700 & 1200 & 1380 \\
\hline Pelampung & 203 & 0 & 200 \\
\hline Tempat Sampah & 255 & 145 & 10 \\
\hline Jumlah & 1158 & 1345 & 1590 \\
\hline
\end{tabular}

(Sumber: PT Duaroda Saranatama)

Berdasarkan data di atas dapat dilihat permintaan akan Cooler Box yang cenderung meningkat dibandingkan dengan permintaan produk lainnya. Untuk produk pelampung, tidak dilakukan penyablonan saat masuk bagian finishing. Lalu untuk produk tempat sampah, penyablonan dilakukan hanya dibagian badan depan. Sedangkan untuk produk cooler box, penyablonan dilakukan di paling sedikit di tiga sisi (atas, badan depan, dan badan belakang). Oleh sebab itu bagian finishing khususnya bagian sablon sangat dituntut untuk bekerja cepat guna memenuhi pesanan yang ada.

Berdasarkan diskusi dengan beberapa karyawan di PT Duaroda Saranatama didapatkan informasi bahwa penempatan pekerja di lokasi khususnya bagian finishing masih sesuai dengan keinginan pekerja.Selain itu dengan tidak adanya standar untuk penempatan pekerja juga dapat mengakibatkan terjadinya keterlambatan dalam penyelesaian proses produksi. Contohnya keterlambatan produksi karena pekerja yang tidak cocok dengan tugas yang dioperasikannya.

Tidak adanya standardisasi penempatan pekerja untukproduksi dapat mengakibatkan dampak buruk bagi perusahaan. Antara lain adalah aliran proses produksi yang tidak konsisten, adanya serangkaian proses yang terputus dan tidak sesuai dengan jadwal yang ditetapkan, dan adanya ketidaksesuaian antara target produksi dengan hasil produksi. Selain itu dengan adanya ketidaksesuaian ini secara langsung akan meningkatkan biaya yang ditimbulkan. Antara lain biaya lembur, biaya operasional, biaya utilitas, dan biaya lainnya. Hal ini berakibat pada proses bisnis PT Duaroda Saranatama yang kurang efektif. Dengan adanya penempatan pekerja yang sesuai dengan kompetensinya maka akan memberikan acuan dalam pelaksanaan prosedur terkait yang secara detail.

Dengan penelitian ini, diharapkan PT Duaroda Saranatama dapat menyelesaikan persoalan yang disebabkan belum dilakukannya pengukuran waktu kerja dalam penyelesain produk cooler box di PT Duaroda Saranatama tepatnya dibagian finishing. Belum adanya riset berkenaan dengan kompetensi pekerja dengan tugas yang dilaksanakannya berdasarkan waktu baku pengerjaan per pekerja. Dan juga karena belum adanya penyesuaian penempatan pekerja pada bagian finishing PT Duaroda Sarantama. Diharapkan pula penelitian ini akan meningkatkan performa dan meningkatkan efisiensi perusahaan tersebut.

\section{DASAR TEORI}

\section{A. Penugasan}

Setiap perusahaan sudah seharusya mengoptimalkan sumberdayanya, baik yang 
berupa bahan baku, tenaga kerja, modal, mesin, dan peralatan serta penggunaan jam kerja. Manusia atau tenaga kerja dengan kualifikasinya memiliki kemampuan, produktivitas dan tugas yang berbeda - beda, akan tetapi, produktivitas itu dapat ditingkatkan apabila perusahaan menempatkan tenaga kerja pada tempat yang tepat (the right man in the right place). Untuk mencapai tujuan tersebut, perusahaan dapat menggunakan metode penugasan (assigment method) (Zulfikarijah, 2004).

Model penugasan adalah suatu model yang berhubungan dengan jaringan, dimana model ini merupakan model khusus dari suatu model program linear yang serupa dengan model trasportasi. Perbedaan model penugasan dengan model trasportasi adalah dalam model penugasan kuantitas suatu pinggiran kolom maupun pinggiran barisnya dibatasi sebanyak satu unit (Sitinjak, 2006).

Metode penugasan (assignment method) merupakan bagian dari linier programming yang digunakan untuk mengalokasikan pekerjaan kepada subjek/ orang tertentu agar diperoleh hasil yang optimal (biaya yang minimal/ keuntungan yang maksimal/ waktu yang minimal, dan lain-lain). Alat analisis metode ini menggunakan pendekatan metode Hungarian. Metode ini bersifat saling meniadakan, artinya apabila seseorang telah mengerjakan satu jenis pekerjaan maka tidak dapat mengerjakan pekerjaan yang lain (satu orang mengerjakan satu pekerjaan dan pekerjaan dikerjakan oleh satu orang (Wijaya, 2013). Model penugasan digunakan untuk menyelesaikan one-to-one masalah penugasan tradisional dari penugasan para pekerja dengan pekerjaan - pekerjaan, para pekerja dengan mesin - mesin, mesin - mesin dengan pekerjaan - pekerjaan, dan lainnya (Weiss, 2005).

Metode Hungarian adalah metode yang memodifikasi baris dan kolom dalam matriks efektifitas sampai muncul sebuah komponen nol tunggal dalam setiap baris atau kolom yang dapat dipilih sebagai alokasi penugasan (Yulistiana, Chaerani, \& Lesmana, 2015). Semua alokasi penugasan yang dibuat adalah alokasi yang optimal, dan saat diterapkan pada matriks efektifitas awal, maka akan memberikan hasil penugasan yang paling minimum (Prawirosentono, 2005). Penyusunan masalah penugasan dengan minimasi adalah sebagai berikut:

1. Menyusun tabel tugas

2. Melakukan pengurangan baris dengan cara memilih item tterkecil tiap baris dan mengurangkannya ke setiap angka di baris tersebut.

3. Jika didapati hasil 0 disetiap kolom, maka dapat diproses ke tahap selanjutnya. Namun jika belum, maka angka terkecil di kolom yan gtidak memiliki 0 harus dikurangkan ke setiap angka dikolom tersebut.

4. Lalu bentuklah penugasan minimum dengan membentuk garis pada nilai yang memiliki banyak 0 .

Ndururu dkk (2017:216) mengatakan bahwa langkah - langkah penyelesaian metode Hungarian(untuk maksimasi) adalah sebagai berikut :

1. Lakukan operasi baris, yaitu dengan mengurangkan semua nilai pada baris dengan nilai terbesarnya (operasi per baris untuk mendapatkan nilai 0 pada tiap barisnya).

2. Lakukan operasi kolom untuk memastikan bahwa pada tiap kolom ada nilai 0 ( lakukan pengurangan terhadap nillai terbesar hanya pada kolom yang tidak memuliki nilai 0 ).

3. Lakukan penugasan terbaiknya (merujuk kepada elemen-elemen yang bernilai 0 atau terbesar, dipilih dan dipilah sendiri), dengan cara :

1) Penugasan pertama kali pada baris dan kolom yang memiliki satu-satunya nilai 0

2) Penugasan berikutnya pada baris saja atau kolom saja yang memiliki satusatunya nilai 0

3) Kerjakan terus hingga selesai dan diperoleh nilai terbesar

\section{B. Aplikasi POM for Windows}

Salah satu aplikasi yang dapat membantu pengerjaan penugasan adalah POM for windows. Menurut (Weiss, 2005), versi pertama aplikasi ini berbentuk DOS yang dipublis di tahun 1989 sebagai PC-POM. Selanjutnya versi DOS diberi nama AB:POM. Versi windows pertama yaitu QM for windows (versi 1.0), didistribusikan pada musim panas 1996 merupakan program terpisah tetapi teteap sejenis. DS for Windows terdiri dari modul dari POM dan QM dan dengan buku manual yang pertama kali didistribusikan tahun 1997. Versi 
kedua dari tiga program tersebut dibuat untuk windows 95dan didistribusikan pada musim gugur 1999. Dan saat ini berkembang dengan versi ketiga.

\section{METODE DAN TEKNIK PENGUKURAN}

Penelitian ini dilaksanakan di PT Duaroda Saranatama yang beralamat di Jl. Raya Cicadas No.169, Gunung Putri, Kabupaten Bogor, Jawa Barat. adapun tahapan penelitiannya adalah sebagai berikut :

A. Studi Pendahuluan

Studi pendahuluan dilakukan untuk mengetahui bagaimana alur hingga hasil penelitian sejenis yang telah ada dengan melihat beberapa penelitian terdahulu.

B. Studi Pustaka

Studi pustaka dilakukan dengan mereview beberapa literatur untuk melihat alur penelitian. Juga mencari teori yang berkenaan dengan penelitian ini yaitu dengan konsep penugasan dengan metode Hungarian.

C. Rumusan Masalah

Berdasarkan uraian permasalahan yang telah dipaparkan di bagian sebelumnya, maka dapat dirumuskan permasalahan yang akan dikaji dalam laporan ini, yaitu:

1. Bagaimanakah hasil pengukuran waktu kerja dalam penyelesain produk cooler box di PT Duaroda Saranatama tepatnya dibagian finishing?

2. Bagaimanakah hasil penempatan antara pekerja berdasarkan waktu baku pengerjaan per pekerja?

3. Bagaimanakah penyesuaian penempatan pekerja berdasarkan proporsi kesalahan pada bagian finishing di PT Duaroda Saranatama?

D. Tujuan Penelitian

Berdasarkan perumusan masalah yang telah dijelaskan, maka tujuan penelitian yang dilaksanakan di PT Duaroda Saranatama ini adalah :

1. Mengetahui lamanya pengerjaan penyelesaian produk cooler box di PT Duaroda Saranatama tepatnya dibagian finishing.
2. Mengetahui penempatan pekerja dengan mesin yang dioperasikannya berdasarkan waktu baku pengerjaan per pekerja.

3. Mengetahui penempatan pekerja berdasarkan proporsi kesalahan pada bagian finishing di PT Duaroda Saranatama.

E. Pengumpulan Data

1. Data primer

Dalam penelitian dengan topik penugasan ini, dilakukan pengambilan data primer antara lain waktu pengerjaan penyablonan dari produk cooler box yaitu produk Bintang Radler, Susu Nasional, Big C'Frut, dan KPBS Pengalengan;dilakukan juga pengumpulan data proporsi kesalahan dalam pengerjaan produk yang dihasilkan, lingkungan kerja juga menjadi data primer yang dikumpulkan

2. Data Sekunder

Untuk data sekunder sebagai pendukung diambil data berkenaan dengan bisnis perusahaan, hingga manajemen perusahaan.

F. Pengolahan Data

Pengolahan data dilakukan dengan melakukan uji keseragaman dan kecukupan datadengan tingkat keyakinan $95 \%$ dan tingkat ketelitian sebesar 5\% untuk data waktu pengerjaan produk. Setelah itu dilakukan pengambilan keputusan untuk diolah ke tahap selanjutnya. Jika data tidak seragam dan tidak cukup, maka harus dikembalikan ke pengumpulan data. Selanjutnya mengukur waktu kerja dengan menambahkan penyesuaian dengan metode Shumarduntuk waktu normal. Kemudian ditambahkan pula kelonggaran untuk waktu baku. Dari hasil pengukuran waktu kerja ini akan dibuat rancangan penugasan operator. Kemudian membuat penugasan berdasarkan proporsi kesalahan yang dilakukan penyablon. Dan juga melakukan perhitungan penugasan berdasarkan waktu baku dan proporsi kesalahan dengan software POM for windows versi 3.0

G. Analisis

Dalam analisis dilakukan pengulasan penugasan berdasarkan perhitungan waktu baku dan juga proporsi kesalahannya dan dilakukananalisis perbandingan penugasan berdasarkan dua faktor yang diuji tersebut. 
H. Kesimpulan dan Saran

Sebagai penutup dari laporan ini, dibuatlah kesimpulan dan saran yang akan menjadi masukan bagi perusahaan.

\section{HASIL DAN PEMBAHASAN}

\section{A. Hasil Perhitungan dengan software POM 3.0 for windows}

Untuk analisis dilakukan perhitungan menggunakan software POM 3.0 for windows sebagai perbandingan dengan perhitungan manual. Berikut merupakan hasil perhitungan dengan menggunakan software POM 3.0 for windows:

\section{Berdasarkan Waktu Pengerjaan}

Dengan bantuan software POM 3.0 for window. Berikut adalah hasil pengerjaannya:

Tabel 3.Matrik Penugasan

\begin{tabular}{|l|r|r|r|r|}
\hline $\begin{array}{l}\text { Optimal cost = } \\
\text { \$789 }\end{array}$ & Grup 1 & Grup 2 & Grup 3 & Grup 4 \\
\hline Bintang Radler & 454 & 427 & 453 & Assign 426 \\
\hline Susu Nasional & 180 & 157 & Assign 174 & 165 \\
\hline Big C'Frut & 153 & Assign 135 & 155 & 148 \\
\hline KPBS Pengalengan 4 & Assign 54 & 51 & 58 & 51 \\
\hline
\end{tabular}

(Sumber : Output POM 3.0 for Windows)

Data di atas merupakan data penugasan optimal tiap pekerjaan dengan grup pengerjaannya. Dengan margin waktu dan resume waktu pengerjaan sebagai berikut:

Tabel 4.Matrik Margin Waktu

\begin{tabular}{|l|r|r|r|r|}
\hline & Grup 1 & Grup 2 & Grup 3 & Grup 4 \\
\hline Bintang Radler & 23 & 12 & 18 & \\
\hline Susu Nasional & 10 & 3 & & \\
\hline Big CFrut & 2 & & & 2 \\
\hline KPBS Pengalengan 4 & & 13 & & 2 \\
\hline
\end{tabular}

(Sumber : Output POM 3.0 for Windows)

Tabel 5. Resume Waktu dalam Penugasan

\begin{tabular}{|l|r|r|}
\hline JOB & $\begin{array}{r}\text { Assigned } \\
\text { to }\end{array}$ & Cost \\
\hline Bintang Radler & Grup 4 & 426 \\
\hline Susu Nasional & Grup 3 & 174 \\
\hline Big C'Frut & Grup 2 & 135 \\
\hline KPBS Pengalengan 4 & Grup 1 & 54 \\
\hline Total & & 789 \\
\hline
\end{tabular}

(Sumber : Output POM 3.0 for Windows)

\section{Berdasarkan Jumlah Kesalahan Tabel 6. Matrik Penugasan}

\begin{tabular}{|l|r|r|r|r|}
\hline $\begin{array}{l}\text { Optimal cost = } \\
\text { \$11 }\end{array}$ & Grup 1 & Grup 2 & Grup 3 & Grup 4 \\
\hline Bintang Radler & 8 & 9 & Assign 2 & 11 \\
\hline Susu Nasional & 4 & Assign 3 & 10 & 5 \\
\hline Big C'Frut & Assign 4 & 7 & 7 & 9 \\
\hline KPBS Pengalengan & 12 & 9 & 5 & Assign 2 \\
\hline
\end{tabular}

(Sumber : Output POM 3.0 for Windows)

Data di atas merupakan data penugasan optimal tiap pekerjaan dengan grup pengerjaannya. Dengan margin kesalahan dan resume kesalahan pengerjaan sebagai berikut:

Tabel 7.Matrik Margin Kesalahan

\begin{tabular}{|l|r|r|r|r|}
\hline & Grup 1 & Grup 2 & Grup 3 & Grup 4 \\
\hline Bintang Radler & & 2 & & \\
\hline Susu Nasional & & & 12 & \\
\hline Big C'Frut & & 4 & 9 & 4 \\
\hline KPBS Pengalengan & 11 & 9 & 10 & \\
\hline
\end{tabular}

(Sumber : Output POM 3.0 for Windows)

Tabel 8. Resume Kesalahan dalam Penugasan

\begin{tabular}{|l|r|r|}
\hline JOB & $\begin{array}{r}\text { Assigned } \\
\text { to }\end{array}$ & Cost \\
\hline Bintang Radler & Grup 3 & 2 \\
\hline Susu Nasional & Grup 2 & 3 \\
\hline Big C'Frut & Grup 1 & 4 \\
\hline KPBS Pengalengan & Grup 4 & 2 \\
\hline Total & & 11 \\
\hline
\end{tabular}

(Sumber : Output POM 3.0 for Windows)

Dari hasil perhitungan yang dilakukan menggunakan software POM 3.0 for windows didapati hasil penugasan optimal yang dihasilkan sama dengan hasil penugasan optimal yang dikerjakan dengan cara manual.

\section{B. Penugasan yang dapat Dilakukan}

Dengan perhitungan yang telah dilakukan, dapat dibuat penugasan dengan mempertimbangkan hal-hal sebagai berikut:

1. Kebutuhan Produk dengan Jumlah yang Banyak

Jika perusahaan mendapatkan pesanan dengan jumlah yang banyak, dapat menggunakan penugasan berdasarkan dengan waktu pengerjaanya. Hal ini dimaksudkan untuk mengurangi waktu pengerjaan agar pekerjaan dapat diselesaikan tepat waktu. 
Penggunaan penugasan dengan berdasarkan kepada jumlah kesalahan kurang membantu dalam hal ini, dikarenakan kesalahan dalam bagian ini dapat diperbaiki dan bukan merupakan kesalahan yang menimbulkan barang reject.

2. Kebutuhan Produk dengan Tenggang Waktu yang Cepat

Perusahaan juga dapat menerapkan penugasan berdasarkan dengan waktu pengerjaan produk dalam kasus ini. Dengan mempertimbangkan waktu pengerjaan, maka perusahaan akan melakukakn efisiensi dalam penggunaan waktu. Dan produk dapat selesai sesuai dengan tenggang waktu yang telah ditetapkan.

\section{KESIMPULAN}

Kesimpulan yang dapat diambil pada penelitian ini adalah sebagai berikut :

1. Penempatan pekerja berdasarkan waktu baku pengerjaan masing-masing produk adalah dengan menempatkan Grup 1 untuk pengerjaan produk KPBS Pengalengan, Grup 2 untuk pengerjaan produk Big C'Frut, Grup 3 untuk pengerjaan produk Susu Nasional, Grup 4 untuk pengerjaan Bintang Radler. Dengan penugasan berdasarkan pada waktu pengerjaan akan menekan waktu agar produk yang dihasilkan selesai sesuai dengan waktu yang telah ditentukan.

2. Penempatan pekerja berdasarkan proporsi kesalahan dilakukan dengan menempatkan Grup 1 untuk pengerjaan produk Big C'Frut, grup 2 untuk pengerjaan produk Susu Nasional, Grup 3 untuk pengerjaan Bintang Radler, Grup 4 untuk pengerjaan produk KPBS Pengalengan.

\section{DAFTAR PUSTAKA}

Assiddiq, P. J., Pudjo, D. M., \& Bambang, K. G. (2014). Optimalisasi Pembagian Pekerja Bangunan Menggunakan Metode Hungarian (Studi Kasus Pada CV MHTdi Tanggul).

Basriati, S., \& Lestari, A. (2017). Penyelesaian Masalah Penugasan Menggunakan
Metode Hungarian dan Pinalti (Studi Kasus: CV. Surya Pelangi). Jurnal Sains Matematika dan Statistika, Vol. 3 No.1, 75-81.

Harini, D. (2017). Optimasi Penugasan Menggunakan Metode Hungarian Pada CV. L\&J Express Malang (Kasus Minimasi). Jurnal INTENSIF, Vol 1 No $2,68-74$.

Ndururu, E., Waruwu, F. T., \& Yanny, A. (2017). Alokasi Pekerja pada Suatu Proyek dengan metode Hungarian (Studi Kasus : PT Ira Widya Utama Medan). KOMIK (Konferensi Nasional Teknologi Informasi dan Komputer), Volume 1 nol.

Prawirosentono, S. (2005). Riset Operasi dan Ekonofisika. Jakarta: PT. Bumi Aksara.

Sitinjak, T. J. (2006). Riset Operasi untuk Pengambilan Keputusan Manajerial dengan Aplikasi Excel. Jakarta: Graha Ilmu.

Weiss, H. J. (2005). POM - QM FOR WINDOWS Version 3. New Jersey: Pearson Education Inc.

Wijaya, A. (2013). Pengantar Riset Operasi . Jakarta: Mitra Wacana Media.

Yulistiana, M., Chaerani, D., \& Lesmana, E. (2015). Penerapan Metode Hungarian dalam Penentuan Penjadwalan Matakuliah Optimal (Studi Kasus: Departemen Matematika Universitas Padjadjaran Semester Ganjil 2013-2014). Jurnal Matematika Integratif, Volume 11 No 1, 45-64.

Zulfikarijah. (2004). Operation Research. Malang: Bayumedia Publishing. 
$p-I S S N: 2620-5793$

JITMI Vol.2 No.2, Oktober 2019

e-ISSN : $2685-6123$ 